Check for updates

Cite this: RSC Adv., 2017, 7, 27656

Received 29th October 2016 Accepted 12th May 2017

DOI: 10.1039/c6ra26025j

rsc.li/rsc-advances

\section{Simultaneous determination of ultra-low traces of lead and cadmium in food and environmental samples using dispersive solid-phase extraction (DSPE) combined with ultrasound-assisted emulsification microextraction based on the solidification of floating organic drop (UAEME-SFO) followed by GFAAS}

\author{
Marzieh Sadeghi, (D) *a Ehsan Rostami, ${ }^{a}$ Davood Kordestani, ${ }^{b}$ Hojat Veisi (D) c \\ and Mojtaba Shamsipura
}

Dispersive solid-phase extraction (DSPE) combined with ultrasound-assisted emulsification microextraction (UAEME) has been developed as a novel approach for the determination of lead and cadmium in food and environmental samples prior to graphite furnace atomic absorption spectrometry. SBA-15/CCMet was synthesized and used as a new sorbent for the extraction of metal ions in DSPE. It was characterized by TEM, and FT-IR techniques. After the DSPE step, stripped metal elements were complexed with diethyldithiophosphate (DDTP), and then the complexes were extracted into 1undecanol using UAEME. Variables affecting the performance of both steps were thoroughly investigated and their effects on the selectivity and efficiency of the whole sample preparation process are discussed. Some parameters such as the type and volume of the extraction solvent, sonication time, $\mathrm{pH}$, ionic strength and centrifugation time were evaluated and optimized. Under the optimized conditions, the limits of detection were $0.2 \mathrm{ng} \mathrm{L}^{-1}$ for $\mathrm{Pb}^{2+}$ and $0.5 \mathrm{ng} \mathrm{L}^{-1}$ for $\mathrm{Cd}^{2+}$, with a preconcentration factor of 1800. The optimized method exhibited a good precision level with relative standard deviation (RSD\%) values of $4.8 \%$ and $5.1 \%$ for $0.1 \mu \mathrm{g} \mathrm{L}^{-1} \mathrm{~Pb}^{2+}$ and $\mathrm{Cd}^{2+}$ respectively $(n=7)$. The proposed method was successfully applied to the extraction of $\mathrm{Pb}$ and $\mathrm{Cd}$ in different food and environmental samples. Application of the proposed method to the analysis of fish certified reference material produced results that were in good agreement with the certified values.

\section{Introduction}

Heavy metal contamination presents a significant threat to the ecosystem due to severe toxicological effects on living organisms. The determination of hazardous metal ions (HMIs) is of interest in different areas including environmental analysis, pharmaceutical and food processes, biology and medicine. Since heavy metals in the environment can enter food chains, and finally accumulate in living organisms to produce biological toxicity even at a very trace level, the strict monitoring of heavy metals in environmental substances is of great importance to evaluate the risk of heavy metals for human health; in this case, accurate analytical methods are required.

\footnotetext{
a'Department Chemistry, Razi University, Kermanshah, Iran. E-mail: negarsade@ gmail.com; m.sadeghi@razi.ac.ir; Fax: +98 8334274559; Tel: +98 8334274559

${ }^{b}$ Department Chemistry, Amir Kabir University of Technology, Tehran, Iran ${ }^{c}$ Department of Chemistry, Payame Noor University, 19395-4697 Tehran, Iran
}

Lead and cadmium are two of the most hazardous elements to human health, because both cause adverse effects on metabolic processes. Cadmium is the sixth most poisonous substance jeopardizing human health. Cd can be harmful to plants and, through accumulation into the food chain, to human health. ${ }^{1}$ Lead is a serious cumulative body poison and enters our body system through food, water, and air. The main target for lead toxicity is the nervous system. The World Health Organization has reported tolerable weekly intakes of $\mathrm{Cd}$ and $\mathrm{Pb}$ as 0.007 and $0.025 \mathrm{mg} \mathrm{kg}^{-1}$ body weight, respectively. ${ }^{2}$

Several advance analytical techniques are available for the determination of trace metals with sufficient sensitivity such as electrothermal atomic absorption spectrometry (ETAAS) and inductively coupled plasma optical emission spectrometry (ICP OES) as well as other methods. ${ }^{3}$ Because of electrothermal atomic absorption spectrometry (ETAAS) only requires a few microliters of sample to carry out the determination, and DLLME involves preconcentration in a small volume of solvent, 
the DLLME-ETAAS combination is of a particular interest. In this way a procedure able to compete with ICP-MS as regards sensitivity results, as demonstrated in a number of recent articles. $^{4-6}$

The analysis of elements in trace levels is a difficult analytical task, mostly due to the complexity of the matrix and the low concentration of these elements, which requires sensitive instrumental techniques and often a preconcentration step. ${ }^{\mathbf{4} 7-\mathbf{9}}$ For this reason, a preliminary separation and preconcentration step is often required to enhance the sensitivity of the method. Several methods involving preconcentration techniques, such as liquid-liquid extraction (LLE) or solid phase extraction (SPE) have been developed for the quantification of trace elements. However, conventional LLE consumes large amounts of the high costing and potentially hazardous organic solvents. In addition, in trace analysis, a large volume of sample is often required and its handling can be extremely time-consuming besides being tedious. The liquid phase microextraction (LPME) technique efficiently overcomes these problems by reducing the amount of organic solvent and combining extraction, preconcentration and sample introduction in one step.

Modern trends in analytical chemistry are towards the simplification and miniaturization of sample preparation procedures. LPME has emerged in these last years as a powerful tool for preconcentration and matrix separation prior to detection. Dispersive liquid-liquid microextraction (DLLME) is based on ternary component solvent systems, in which a mixture of extracting and dispersive solvent is rapidly injected into an aqueous sample containing the analytes of interest, which causes the formation of a cloudy solution. In DLLME, disperser solvent is miscible in both aqueous and organic phases. ${ }^{10}$ On the other hand, adding disperser solvent such as methanol in water, the interfacial tension of mixture decreases which it seems play an important role in dispersion of organic solvent in water by increasing the surface area between the organic and aqueous sample. ${ }^{\mathbf{1 1}}$ Hereon, the surface area between the extraction solvent and aqueous phase (sample) is infinitely large and phase transition of analyte into the organic phase is fast. Hence, equilibrium state achieves fast, leading to a very short extraction time.

Despite of undeniable benefits of DLLME, the use of disperser solvent usually decreases the partition coefficient of analytes into the extractant solvent and also it can complicate the phase separation process. To overcome these problems, a new mode of liquid-phase microextraction, namely ultrasound-assisted emulsification microextraction (USAEME) has been developed. ${ }^{12}$ In this method, an extraction solvent is dispersed into aqueous solution by ultrasound radiation without addition of any water-miscible organic dispersive solvent. Ultrasound radiation can lead to a process named cavitation. In cavitation process, bubble in a liquid rapidly collapses, producing a shock wave. Sufficient energy of this shock can break down the droplet of dispersed phase and generate a smaller droplet size immediately after disruption, thus enhancing the emulsification. ${ }^{13}$ As a consequence, the ultrasound radiation is an efficient tool to accelerate the mass- transfer process between two immiscible phases, leading to an increment in the extraction efficiency of the technique in a minimum amount of time. ${ }^{\mathbf{1 4}}$ The method is also modified by the advantages of solidification of a floating organic (SFO) droplet (USAEME-SFO). In this technique, low density solvents having near room temperature melting points was used as extraction solvent, solidified in ice bath after its centrifugation and can be collected easily without using any specific holders.

Dispersive solid phase extraction (DSPE) ${ }^{15}$ is another novel sample preparation technique which offers unique advantages such as simplicity, low solvent use, high cost effectiveness, safety, and automation. The sorbent in DSPE is directly added into the sample solution containing the target analytes without forming a column or conditioning. The choice of appropriate sorbent is a critical factor to obtain good recovery and high enrichment factor in SPE procedure.

Ordered mesoporous materials have gained considerable interest due to their potential applications in adsorption, catalysis and preparation of advanced nanostructured materials with remarkable physical and chemical properties. ${ }^{16,17}$ Among mesoporous silica materials, SBA-15 has relatively good hydrothermal stability, and possesses hexagonal arrays of uniform pores with high special surface area and large pore volume. ${ }^{18}$

Newly synthesized amine-functionalized SBA-15 was used as DSPE sorbent. The structural evaluation studies of sorbent were performed with various experimental techniques such as transmission electron microscopy (TEM), Fourier transform infrared spectroscopy (FT-IR).

In this study, functionalized SBA-15/CCmet was synthesized and used as a new sorbent for the extraction of metal ions. The aim of this study was the combination of dispersive solid phase extraction (DSPE) with ultrasound-assisted emulsification microextraction (USAEME) for the highly efficient extraction and determination of ultra trace amounts of $\mathrm{Pb}^{2+}$ and $\mathrm{Cd}^{2+}$ ions using graphite furnace atomic absorption spectrometry (GFAAS). The influence of different experimental parameters on the performance of both the steps were thoroughly investigated and discussed. Finally, the applicability of the proposed method was tested by the determination of lead and cadmium in food and environmental samples. In addition, the accuracy of the proposed methodology was evaluated by analyzing a standard reference material.

\section{Experimental}

\subsection{Instrumentation}

Transmission electron microscopy (TEM) measurements were performed using a Philips CM10 operated at $100 \mathrm{kV}$ electron beam accelerating voltage. Scanning electron microscopy (SEM) measurements were obtained using a Philips XL30. Thermo gravimetric analyses (TGA) were performed on a NETZSCH TG 209 F1 Iris analyzer with a dynamic temperature program of 25$800{ }^{\circ} \mathrm{C}$. All measurements were carried out using a Model nov AA400 atomic absorption spectrometer (Analytik Jena AG, Jena, Germany), equipped with deuterium background correction, a transversely heated graphite tube atomizer and MPE 60 autosampler. Pyrolytic graphite coated graphite tubes with 
Table 1 The graphite furnace temperature program for determination of lead and cadmium

\begin{tabular}{|c|c|c|c|c|c|}
\hline Steps & \multicolumn{2}{|c|}{ Temperature $\left({ }^{\circ} \mathrm{C}\right)$} & \multicolumn{2}{|l|}{ Time (s) } & $\begin{array}{l}\text { Argon flow rate } \\
\left(\mathrm{mL} \mathrm{min}^{-1}\right)\end{array}$ \\
\hline Pyrolysis & 600 & 650 & 250 & 10 & 500 \\
\hline Atomization & 1200 & 1200 & 1500 & 5 & 0 \\
\hline Cleanout & 2300 & 2300 & 500 & 4 & 500 \\
\hline
\end{tabular}

integrated PIN platform (Analytik Jena Part No. 407-A81.026) were used for all measurements. The inert gas was argon flowing at $250 \mathrm{~mL} \mathrm{~min}^{-1}$. Lead and cadmium hollow cathode lamps (Analytik Jena, Jena, Germany) were used as the radiation sources. The instrumental parameters were as follows: wavelength $283.3 \mathrm{~nm}\left(\mathrm{~Pb}^{2+}\right)$ and $228.8 \mathrm{~nm}\left(\mathrm{Cd}^{2+}\right)$ slit width: $0.8 \mathrm{~nm}$ and lamp current: $3.0 \mathrm{~mA}$. The optimum operating parameters for GFAAS determination of $\mathrm{Pb}^{2+}$ and $\mathrm{Cd}^{2+}$ are given in Table 1. The $\mathrm{pH}$ values were measured with a Metrohm $\mathrm{pH}$-meter (Model: 692, Herisau, Switzerland) supplied with a glasscombined electrode. A Hettich Zentrifugen (EBA20, Tuttlingen, Germany) was used for centrifugations.

\subsection{Reagents and samples}

Analytical-grade tetraethylorthosilicate (TEOS), 3-aminopropyltrimethoxysilane (APTES), THF, acetonitrile, hydrogen peroxide, nitric acid, hydrochloric acid and ammonia were supplied from Merck (Darmstadt, Germany). 1-Undecanol, 2undecanol, 1-octanol, $n$-hexane as extraction solvents were acquired from Merck. The chelating agent, diethyl dithiophosphate (DDTP) with the density of $1.17 \mathrm{~g} \mathrm{~mL}^{-1}$ was supplied from Merck. Pluronic P123 triblock copolymer, metformin hydrochloride, 3-aminoropropyl trimethoxysilane (APTMS), diisopropylethylamine and cyanoric chloride were purchased from Sigma-Aldrich.

Analytical grade nitrate salts of $\mathrm{Pb}^{2+}$ and $\mathrm{Cd}^{2+}$ (from Merck) were of the highest purity available and used without any further purification. All solutions were prepared in doubledistilled deionized water. The stock metal ion solutions (1000 $\mathrm{mg} \mathrm{L}^{-1}$ ) of $\mathrm{Pb}^{2+}$ and $\mathrm{Cd}^{2+}$ were prepared by dissolving the appropriate amounts of nitrate salts. Working standard solution was obtained by appropriate dilution of the stock standard solution.

\subsection{Synthesis of amine denderon groups in SBA-15 (SBA-15/ CCMet)}

The synthesis of SBA-15 was performed following a well-known procedure. ${ }^{19,20}$ In short explanation for the SBA-15 synthesis, $4.0 \mathrm{~g}$ of pluronic $\mathrm{P} 123$ was dissolved in $50 \mathrm{~mL}$ of water and stirred for $5 \mathrm{~h}$ at room temperature. The mixture was added to $120 \mathrm{~mL}$ of $2 \mathrm{~mol} \mathrm{~L}^{-1}$ hydrochloric acid solution and remained for $2 \mathrm{~h}$. Then, $8.5 \mathrm{~g}$ of TEOS was added to that solution and stirred for $24 \mathrm{~h}$ at $35{ }^{\circ} \mathrm{C}$. The mixture was then aged at $80{ }^{\circ} \mathrm{C}$ for $24 \mathrm{~h}$ without stirring. After completion of the reaction, the solid products were filtered, washed with deionized water, and air- dried overnight. The P123 was removed thoroughly with hot ethanol/water $(3: 2)$ using a Soxhlet apparatus for $24 \mathrm{~h}$. It was dried in air at $100{ }^{\circ} \mathrm{C}$ overnight.

The route employed for the synthesis of the SBA/CCMet are shown in Scheme 1. To a $100 \mathrm{~mL}$ of round-bottom flask were introduced $30 \mathrm{~mL}$ of anhydrous toluene and $3.0 \mathrm{~g}$ of SBA-15 and $0.18 \mathrm{~g}$ ( $1.5 \mathrm{mmol})$ of 3-aminoropropyl trimethoxysilane (APTMS) were added. The solution was refluxed for $24 \mathrm{~h}$ under an inert atmosphere, filtered and washed subsequently with toluene, dichloromethane, and methanol, and dried under reduced pressure at $80{ }^{\circ} \mathrm{C}$ for $10 \mathrm{~h}$. In another $100 \mathrm{~mL}$ round-bottom flask, to a solution of $3 \mathrm{~g}$ of aminopropyl functionalized SBA15 in $35 \mathrm{~mL}$ of $\mathrm{THF}, 0.5 \mathrm{~mL}$ of diisopropylethylamine was added. Then, $0.46 \mathrm{~g}$ ( $3 \mathrm{mmol})$ of cyanoric chloride was added in $0{ }^{\circ} \mathrm{C}$. After $2 \mathrm{~h}$, the solution was decanted and washed with $2 \times$ 25 of fresh THF and decanted. Then, $25 \mathrm{~mL}$ of acetonitrile and 1 $\mathrm{mL}$ of diisopropylethylamine was added to residue. $0.91 \mathrm{~g}$ of free metformin $(7 \mathrm{mmol})$ was added to the mixture and stirred. After completion of the reaction, the solid products were filtered, washed with deionized water and then acetone and dried at $50{ }^{\circ} \mathrm{C}$ for $12 \mathrm{~h}$. The clung metformin on triazine functionalized SBA-15 (SBA-15/CCMet) was obtained through this simple procedure. ${ }^{21}$

\subsection{Extraction procedure}

The general procedure for extraction of ions by SBA-15/CCMet was as follows: SBA-15/CCMet as solid-phase extraction sorbent was used for the extraction of $\mathrm{Pb}^{2+}$ and $\mathrm{Cd}^{2+}$ from the aqueous samples. To a suitable volume $(100 \mathrm{~mL})$ solution of $\mathrm{Pb}^{2+}, \mathrm{Cd}^{2+}$ and (at $\mathrm{pH}=7.5$ ), $10 \mathrm{mg}$ of SBA-15/CCMet was added and the mixture was stirred for at least $10 \mathrm{~min}$. In the case of food and environmental sample, the final volume after digestion reached to $100 \mathrm{~mL}$ in a volumetric flask. Then $10 \mathrm{mg}$ of SBA-15/CCMet was added to final solution and the mixture was stirred for at least $10 \mathrm{~min}$. Then the resulting mixture was centrifuged for $5 \mathrm{~min}$ at $5000 \mathrm{rpm}$. After the extraction, the extracted ions by the SBA-15/CCMet were stripped using $5 \mathrm{~mL}$ of $0.2 \mathrm{~mol} \mathrm{~L}^{-1}$ solution of nitric acid. The eluent $\mathrm{pH}$ was adjusted to $\mathrm{pH} 3$ with sodium acetate solution $\left(0.1 \mathrm{~mol} \mathrm{~L}^{-1}\right)$. DDTP was utilized as the chelating agent for extraction of $\mathrm{Pb}^{2+}$ and $\mathrm{Cd}^{2+}$. The optimum concentration of chelating agent $(0.03 \%(\mathrm{v} / \mathrm{v})$ of DDTP) was added into the metal solution. $\mathrm{Pb}^{2+}$ and $\mathrm{Cd}^{2+}$ reacted with DDTP in the form of hydrophobic complex which could be extracted into the dispersed fine droplets. Then $40 \mu \mathrm{L}$ of extractant (1-undecanol) was injected quickly into the solution 


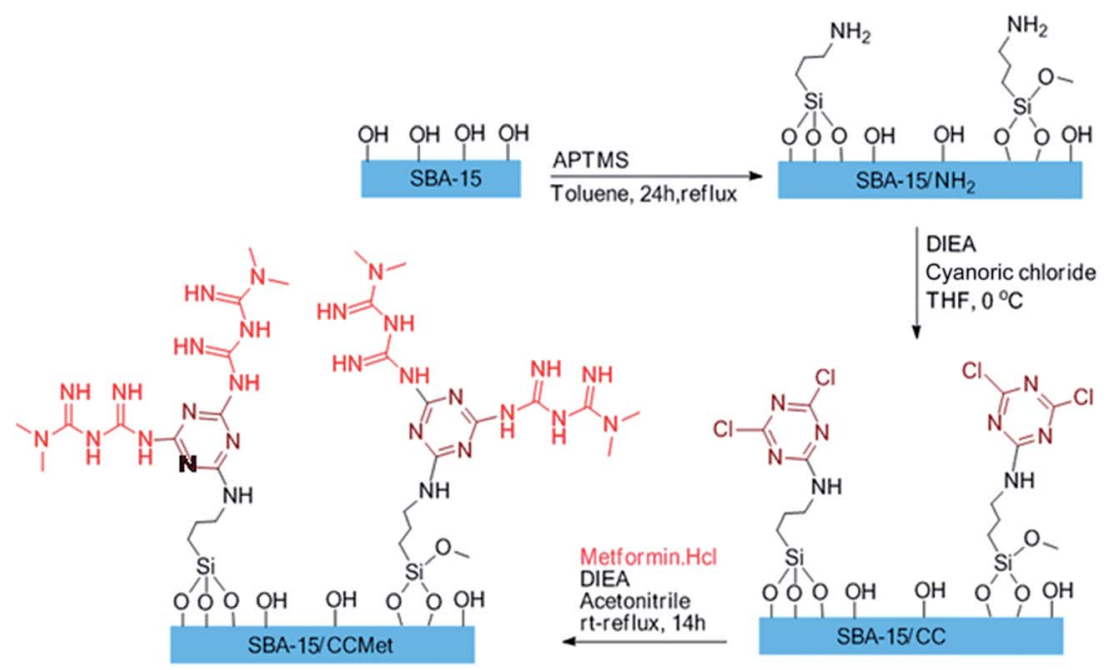

Scheme 1 Route employed for the synthesis of the SBA/CCMet.

by using a syringe. The mixture was homogenized by shaking with hand for a few seconds, then, the solution was sonicated in ultrasonic bath for $3 \mathrm{~min}$. A cloudy solution, resulting from the dispersion of the fine 1-undecanol droplets in the aqueous solution, was formed in the test tube. In this step, the metal ion complexes were extracted into the fine droplets of 1-undecanol. The mixture was then centrifuged for $5 \mathrm{~min}$ at $5000 \mathrm{rpm}$. Accordingly, the dispersed fine droplets of the extraction phase were collected on the top of the conical test tube. The test tube was transferred into a beaker containing ice pieces and the organic solvent was solidified, then the solidified solvent was transferred into a vial, where it melted immediately. Finally, 10 $\mu \mathrm{L}$ of collected extraction solvent using an auto-sampler was injected into the GFAAS. The extraction set-up for DSPEUAEME-SFO is illustrated in Scheme 2.

\subsection{Sample collection and preparation}

2.5.1. Water samples. Water samples including river water (Gharaso and Saymareh River) and well water were collected from west of Iran. All the above real-water samples were filtered to remove any suspended particulate matter and stored at $4{ }^{\circ} \mathrm{C}$ in a refrigerator before use. Final aqueous solution was subjected to DSPE-USAME-SFO procedure.

2.5.2. Rice. Three Iranian rice samples were purchased from a local supermarket in Kermanshah. $0.1000 \mathrm{~g}$ of powdered rice samples dissolved in $10 \mathrm{~mL}$ concentrated $\mathrm{HNO}_{3}$ and heated

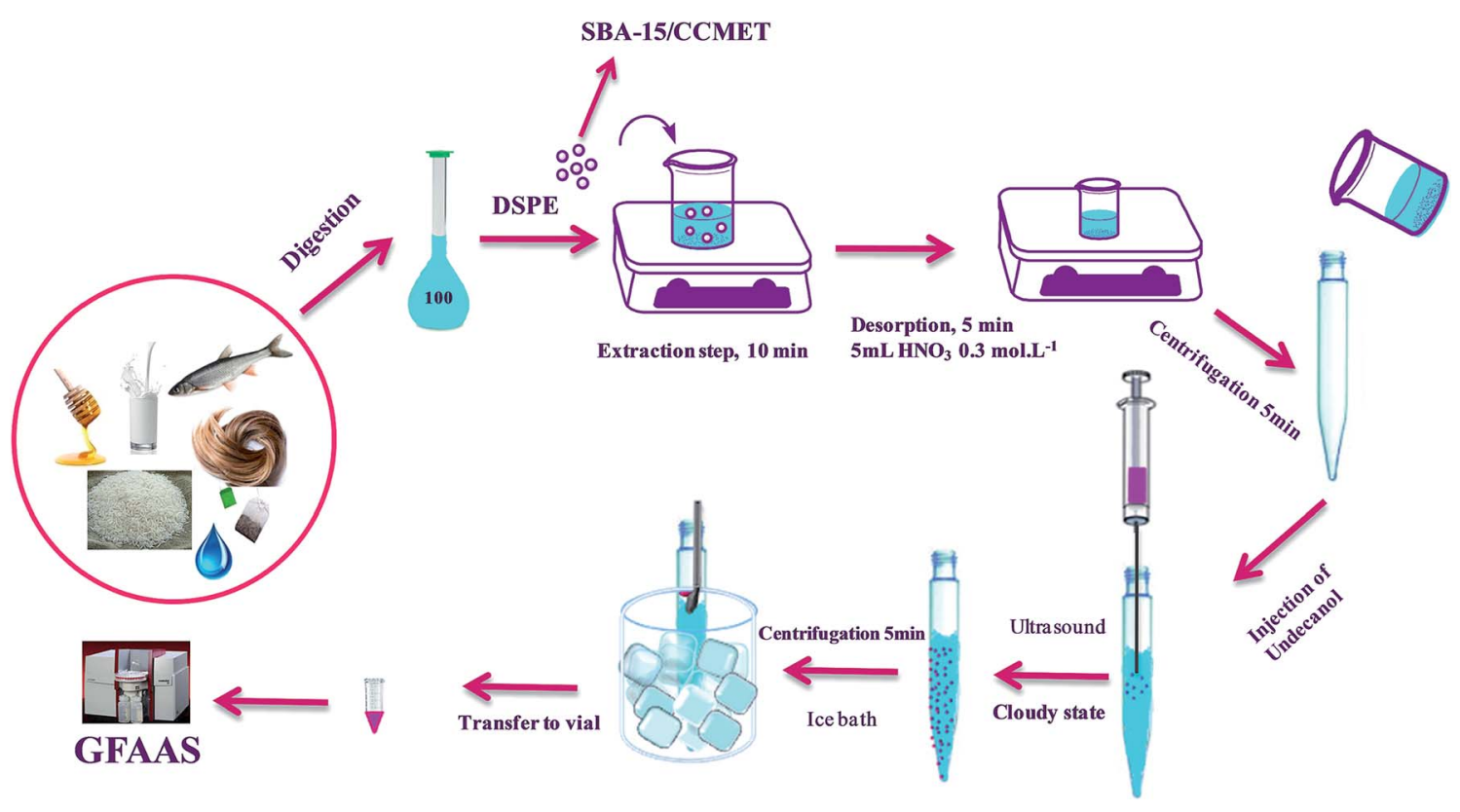

Scheme 2 Schematic diagram of DSPE-UAEME-SFO extraction method. 
on a hot plate at a low temperature. Then, $3 \mathrm{~mL}$ of concentrated $\mathrm{HCl}$ was added to the mixture and heated to near dryness. Under the heating conditions, concentrated hydrogen peroxide was added and heated for another hour to complete the digestion. The solution was diluted to $100 \mathrm{~mL}$ with deionized water. The final solution was analyzed according to the analytical procedure.

2.5.3. Human hair. The hair sample was prepared as reported. ${ }^{22}$ Hair samples were collected from the vertex of the scalp by cutting from the scalp region, and the hair length varied between 3 and $5 \mathrm{~cm}$ prior to analysis, all hair samples were cut into $2 \mathrm{~cm}$ with a stainless steel scissor. The hair samples were then washed three times with doubly distilled deionized water, and oven-dried at $100{ }^{\circ} \mathrm{C}$. About $0.1000 \mathrm{~g}$ of the dried sample was placed in a $50 \mathrm{~mL}$ beaker and $5 \mathrm{~mL}$ concentrated $\mathrm{HNO}_{3}(65 \%)$ and $1 \mathrm{~mL}$ concentrated $\mathrm{HClO}_{4}(70-72 \%)$ were added. The content of the beaker was heated on a hot plate (initially at $100{ }^{\circ} \mathrm{C}$ for $20 \mathrm{~min}$ ). After complete dissolution, the solution was cooled to $70{ }^{\circ} \mathrm{C}$ and $3 \mathrm{~mL}$ of $\mathrm{H}_{2} \mathrm{O}_{2}(30 \%)$ was added. The mixture was heated to dryness to yield a whitish residue. About $2 \mathrm{~mL}$ of $0.1 \mathrm{M} \mathrm{HNO}_{3}$ was added to the beaker and the content was heated at $100{ }^{\circ} \mathrm{C}$ for $5 \mathrm{~min}$. After cooling to room temperature, the solution was completely transferred to a calibrated $100 \mathrm{~mL}$ volumetric flask; the $\mathrm{pH}$ was adjusted to $\mathrm{pH}$ 7.5. The resulting sample solution was subjected to DSPE-USAMESFO procedure.

2.5.3.1. Live subject statement. Method of digestion of human hair was done according to pervious method in our department. Human hair sample was collected voluntarily and it is provided from waste haircut of hair dresser.

2.5.4. Fish. Two fish samples (farmed salmon) were obtained from local market in Kermanshah (a city in west of Iran). Each sample was placed in a watch glass, rinsed with water, and dried in an oven at $150{ }^{\circ} \mathrm{C} .0 .1000 \mathrm{~g}$ of dried fish muscle was digested with $3 \mathrm{~mL}$ of concentrated $\mathrm{HNO}_{3}(65 \%)$ and $1 \mathrm{~mL}$ of concentrated $\mathrm{H}_{2} \mathrm{O}_{2}(30 \%)$ and heated for $1 \mathrm{~h}$. The proteins were precipitated and separated during the digestion process. The resulted solution was filtered through a filter paper for remove the precipitated proteins. After digestion; the volume was made up to $100 \mathrm{~mL}$ with deionized water. The $\mathrm{pH}$ of samples was adjusted to 7.5. Final solution was subjected to DSPE-UAEMESFO procedure.

Two certified reference material (DORM-2-dogfish muscle, NRC, Canada; Muscle tissue-NIST SRM 2976) were prepared according above procedure.

2.5.5. Tea. Three of the most widely consumed brands of black tea were purchased from local supermarket in Kermanshah (a city in west of Iran). $0.1000 \mathrm{~g}$ of tea was dissolved in 5 $\mathrm{mL}$ of concentrated $\mathrm{HNO}_{3}(65 \%)$ and heated for $1 \mathrm{~h}$, and then it was filtrated and evaporated to about $1 \mathrm{~mL}$. After digestion, the volume was made up to $100 \mathrm{~mL}$ with deionized water. The $\mathrm{pH}$ of samples was adjusted to 7.5. Final solution was subjected to DSPE-UAEME-SFO procedure.

2.5.6. Honey. All honey samples were provided by the local association of bee keepers with guaranteed origin and made by traditional procedures in the honey-producing region; all samples were collected in clean and closed glass bottles and immediately transferred to the laboratory; all samples were stored in glass bottles and kept at $4{ }^{\circ} \mathrm{C}$ in dark place until analysis. An amount of $0.1000 \mathrm{~g}$ of each sample was digested with $3 \mathrm{~mL}$ of $\mathrm{HNO}_{3}(65 \%)$ and $1 \mathrm{~mL}$ of $\mathrm{H}_{2} \mathrm{O}_{2}$ (35\%). After that, samples were digested in the microwave oven. ${ }^{23}$ After digestion, the volume was made up to $100 \mathrm{~mL}$ with deionized water.

2.5.7. Cow milk. Samples of caw milk were collected from milk collecting centers which were representative of the traditional dairy farms, and transported at $2-4{ }^{\circ} \mathrm{C}$ in an icebox before analysis. A $10.0 \mathrm{~mL}$ of each liquid milk sample was transferred into $100 \mathrm{~mL}$ glass beaker and then $18 \mathrm{~mL}$ of $\mathrm{HNO}_{3}(65 \%)$ and 1 $\mathrm{mL}$ of $\mathrm{H}_{2} \mathrm{O}_{2}(30 \%)$ were added. The content of the beaker was heated on a hot plate for $1 \mathrm{~h}$. The digested solutions were then allowed to cool for $10 \mathrm{~min}$. To the cooled solution, $10 \mathrm{~mL}$ distilled deionized water was added to dissolve the precipitate formed on cooling and gently swirled for a while. The digested samples were then filtered into a $100 \mathrm{~mL}$ flask using Whatman filter paper to remove any suspended or turbid residues. After digestion, the volume was made up to $100 \mathrm{~mL}$ with deionized water.

\section{Results and discussion}

\subsection{Characterization of functionalized SBA-15}

Fig. 1 shows the FT-IR spectra obtained for SBA-15/CCMet. As it is seen, the typical silica bands associated with the main inorganic backbone can be clearly observed in spectrum. The sharp band at $1052 \mathrm{~cm}^{-1}$ is corresponding to $\mathrm{Si}-\mathrm{O}-\mathrm{Si}$ anti-symmetric stretching vibration, being indicative of the existence of a silica material. ${ }^{24}$ Fig. 1 shows the spectrum of SBA-15/CCMet and signal appeared at $3350 \mathrm{~cm}^{-1}$ is attributed to the presence of $\mathrm{N}-\mathrm{H}$ stretching. The bending vibration of amine group is also observed at $1650 \mathrm{~cm}^{-1}$. This assignment is supported by the analysis of the IR spectrum of melamine. ${ }^{25}$ The band in the spectral region of $1251 \mathrm{~cm}^{-1}$ can be assigned to the side chain in plane $\mathrm{C}-\mathrm{N}-\mathrm{C}$ and $\mathrm{N}-\mathrm{C}-\mathrm{N}$ bending of triazine ring. ${ }^{26}$

The morphology and size of the SBA-15/CCMet was determined by TEM images. Typical TEM images obtained for SBA15/CCMet is shown in Fig. 2.

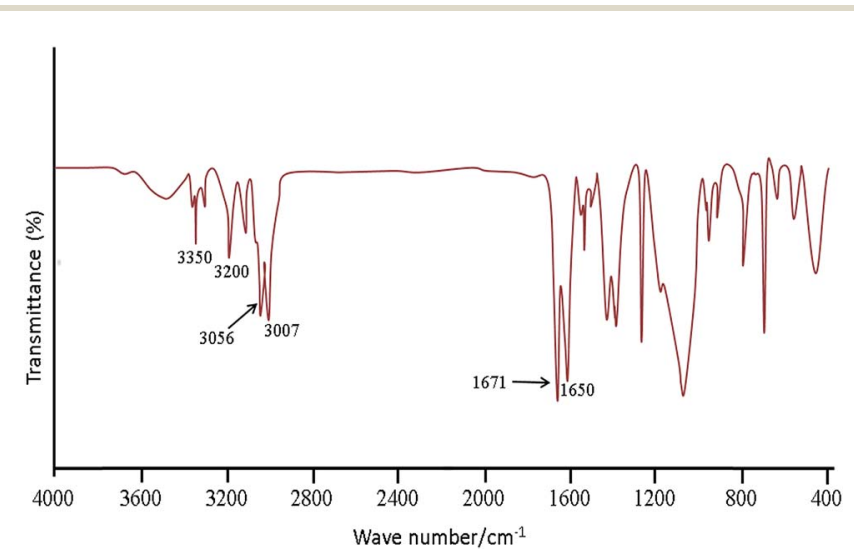

Fig. 1 FT-IR spectra obtained for SBA-15/CCMet. 

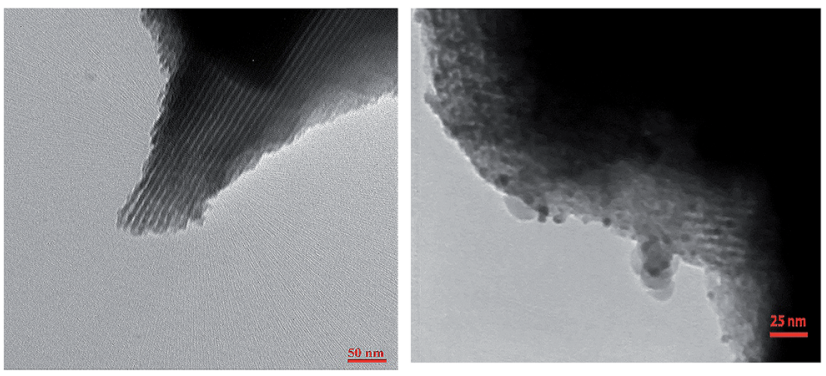

Fig. 2 TEM image of SBA-15/CCMet.

\subsection{Optimization of DSPE-SA-DLLME parameters}

In the present work, DSPE-USAEME combined with GFAAS was developed for the determination of lead and cadmium in food and environmental samples. This combination lead to very high enrichment factor and could be used in complex matrices. In order to obtain a high extraction recovery and enrichment factor with the employment of DSPE-USAEME, the DSPE and USAEME conditions were optimized. In order to reach optimum experimental conditions for quantitative extraction of lead and cadmium ions via DSPE-UASEME, the influence of different parameters affecting the extraction efficiency such as, amount of SBA-15/CCMet, $\mathrm{pH}$, type and volume of extraction and elution solvent, concentration of chelating agent, ultrasonic and centrifugation time, and concentration of salt were investigated.

\subsubsection{Optimization of the DSPE procedure}

3.2.1.1. Effect of the breakthrough volume. In the analysis of heavy metals, the sample volume is one of the important parameters influencing the extraction recovery. In order to achieve a high extraction recovery for sample with very low analyte concentration, a large volume of samples solution is required. The effect of breakthrough volume on the extraction of $0.1 \mu \mathrm{g}$ of $\mathrm{Pb}^{2+}$ and $\mathrm{Cd}^{2+}$ from different sample volumes (50.0 to $2000.0 \mathrm{~mL}$ ) was investigated. The results showed that an

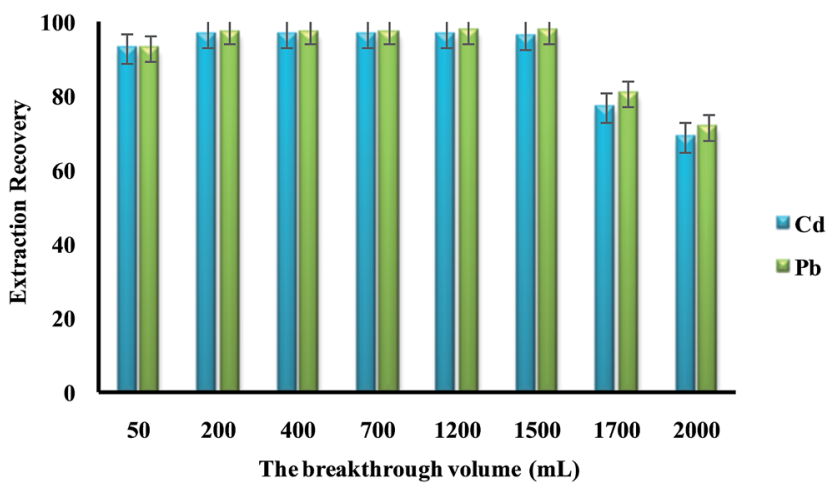

Fig. 3 The effect of the breakthrough volume on the extraction recovery of $\mathrm{Pb}^{2+}$ and $\mathrm{Cd}^{2+}$ by dispersive solid phase extraction. Extraction conditions: amount of SBA-15/CCMet, $10 \mathrm{mg}$; elution solvent (nitric acid) volume, $5.0 \mathrm{~mL}$; concentration of DDTP, $0.04 \%$ (v/ v); extraction solvent (1-undecanol) volume, $40.0 \mu \mathrm{L}$; room temperature; concentration of $\mathrm{Pb}^{2+}$ and $\mathrm{Cd}^{2+}, 0.1 \mu \mathrm{g} \mathrm{L}^{-1}$. acceptable extraction recovery was observed when sample volumes were increased to $1500 \mathrm{~mL}$, which seemed to be the tolerated volume for breakthrough (Fig. 3). Considering the analytical time and trace level of $\mathrm{Pb}^{2+}$ and $\mathrm{Cd}^{2+}$ in water samples, $100 \mathrm{~mL}$ was used as the optimized breakthrough volume.

3.2.1.2. The influence of the $\mathrm{pH}$ on the $\mathrm{Pb}^{2+}$ and $\mathrm{Cd}^{2+}$ ions extraction recovery. The existence of electron donating nitrogen atoms in biguanide and triazide structures was expected to increase the stability of its transition and heavy metal ions complexes over other metal ions, especially alkali and alkaline earth cations. The effect of $\mathrm{pH}$ on the extraction of $\mathrm{Pb}^{2+}$ and $\mathrm{Cd}^{2+}$ from water samples by SBA-15/CCMet was investigated and the results are illustrated in Fig. 4. The $\mathrm{pH}$ of solution was adjusted by either $\mathrm{HNO}_{3}$ or concentrated ammonia. As can be seen from Fig. $4, \mathrm{~Pb}^{2+}$ and $\mathrm{Cd}^{2+}$ can be extracted quantitatively by the SBA-15/CCMet in the $\mathrm{pH} \geq 7.5$. It could be due to the charge-dipole interaction between metal ions and nitrogen atoms of SBA-15/CCMet. But at lower $\mathrm{pH}(\mathrm{pH} \leq 4)$, the nitrogen atoms could be protonated and reduces the stability of the complexes, leading to decrease in extraction efficiency. Thus, in subsequent experiments, a solution of $\mathrm{pH} 7.5$ was used for further studies.

3.2.1.3. Optimization amount of SBA-15/CCMet. In order to study the effect of the amount of SBA-15/CCMet on the quantitative extraction of metal ions, the extraction was conducted by varying the amounts of the SBA-15/CCMet from 1 to $20 \mathrm{mg}$. As shown in Fig. 5, the results indicated that $\mathrm{Pb}^{2+}$ and $\mathrm{Cd}^{2+}$ could be extracted quantitatively using $10 \mathrm{mg}$ of SBA-15/CCMet. Therefore $10 \mathrm{mg}$ of adsorbent selected for subsequent studies.

3.2.1.4. Effect of concentration and volume of eluent. Nitric acid was selected as the eluent and the effect of its concentration in the range of $0.1-2.0 \mathrm{~mol} \mathrm{~L}^{-1}$ on desorption of heavy metal ions was studied. Results showed that $0.2 \mathrm{~mol} \mathrm{~L}^{-1}$ nitric acid solution can accomplish the quantitative elution of $\mathrm{Pb}^{2+}$ and $\mathrm{Cd}^{2+}$ ions from the SBA-15/CCMet. Therefore, an optimum concentration of $0.2 \mathrm{~mol} \mathrm{~L}^{-1}$ of nitric acid was used in the

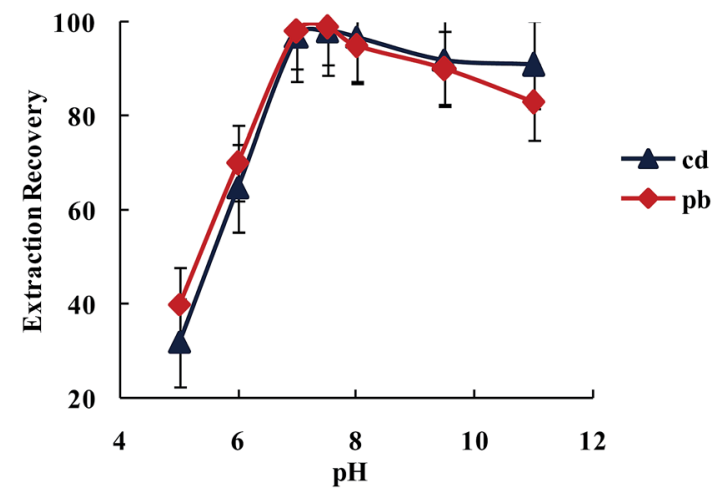

Fig. 4 The effect of the solution $\mathrm{pH}$ on the extraction recovery of $\mathrm{Pb}^{2+}$ and $\mathrm{Cd}^{2+}$ by dispersive solid phase extraction. Extraction conditions: water sample volume, $100 \mathrm{~mL}$, amount of SBA-15/CCMet, $10 \mathrm{mg}$; elution solvent (nitric acid) volume, $5.0 \mathrm{~mL}$; concentration of DDTP, $0.04 \%(\mathrm{v} / \mathrm{v})$; extraction solvent (1-undecanol) volume, $40.0 \mu \mathrm{L}$; room temperature; concentration of $\mathrm{Pb}^{2+}$ and $\mathrm{Cd}^{2+}, 0.1 \mu \mathrm{g} \mathrm{L^{-1 }}$. 


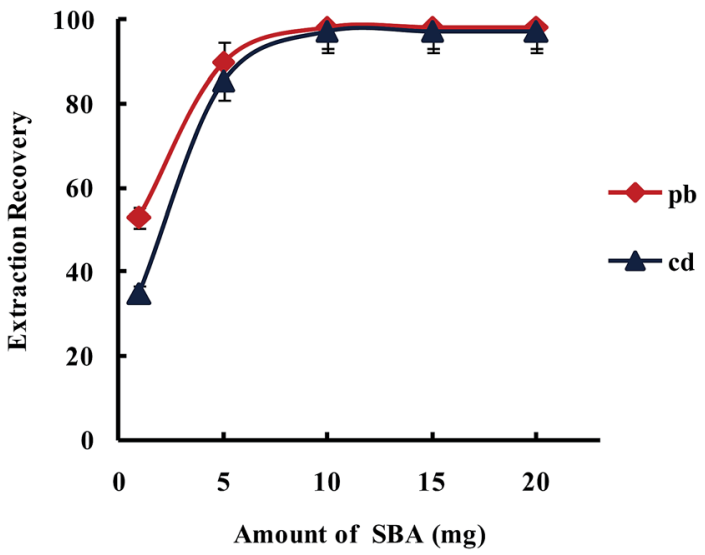

Fig. 5 Effect of amount of SBA-15/Met on the extraction recovery of $\mathrm{Pb}^{2+}$ and $\mathrm{Cd}^{2+}$ with a concentration of $0.1 \mu \mathrm{g} \mathrm{L}^{-1}$ obtained from DSPEUSAEME-SFO. Extraction conditions: similar to those in Fig. 4, except for a sample solution $\mathrm{pH}$ of 7.5 .

future studies. Some experiments were carried out in order to choose a proper volume of nitric acid for the recovery of $\mathrm{Pb}^{2+}$ and $\mathrm{Cd}^{2+}$ ions after extraction by the SBA-15/CCMet. The effect of the volume of eluent on the desorption of metals ions from the SBA-15/CCMet was studied in the range of 1.0-10.0 mL and $5.0 \mathrm{~mL}$ of nitric acid $\left(0.2 \mathrm{~mol} \mathrm{~L}^{-1}\right)$ was found to be sufficient for the quantitative recovery of the analyte.

3.2.1.5. Effect of the extraction time. The effect of the contact time on the efficiency of the extraction for a series of solutions containing $0.1 \mu \mathrm{g} \mathrm{L}^{-1}$ of $\mathrm{Pb}^{2+}$ and $\mathrm{Cd}^{2+}$ ions was studied. The quantitative recoveries of the $\mathrm{Pb}^{2+}$ and $\mathrm{Cd}^{2+}$ were obtained using $7 \mathrm{~min}$ of stirring time. Thus, the mixtures were stirred for $7 \mathrm{~min}$ for all experiments.

\subsubsection{Optimization of USAEME parameters}

3.2.2.1. Effect of concentration of chelating reagent. Diethyldithiophosphate (DDTP) is a well-known chelating agent for lead and cadmium extraction with the formation of a stable $2: 1$ complex with $\mathrm{Pb}^{2+}$ and $\mathrm{Cd}^{2+}$ ions. The effect of concentration of DDTP on extraction recovery of $\mathrm{Pb}^{2+}$ and $\mathrm{Cd}^{2+}$ ions was

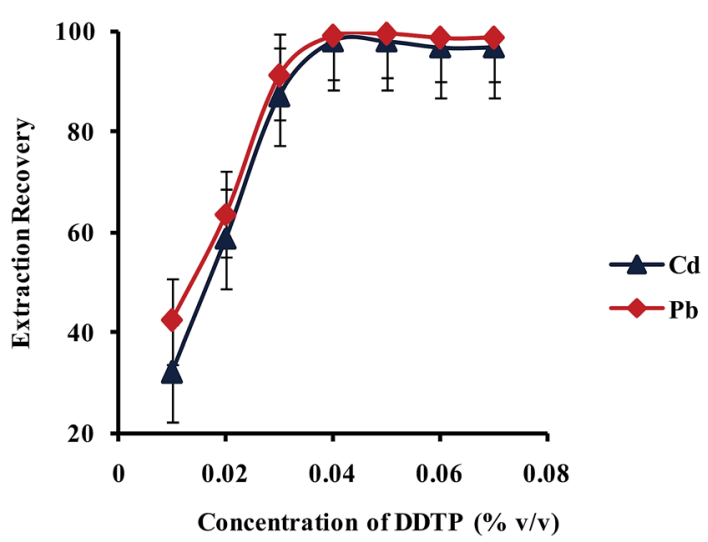

Fig. 6 Effect of concentration of DDTP on the extraction recovery of $\mathrm{Pb}^{2+}$ and $\mathrm{Cd}^{2+}$ obtained from DSPE-UAEME-SFO. Extraction conditions are similar to those of Fig. 4.

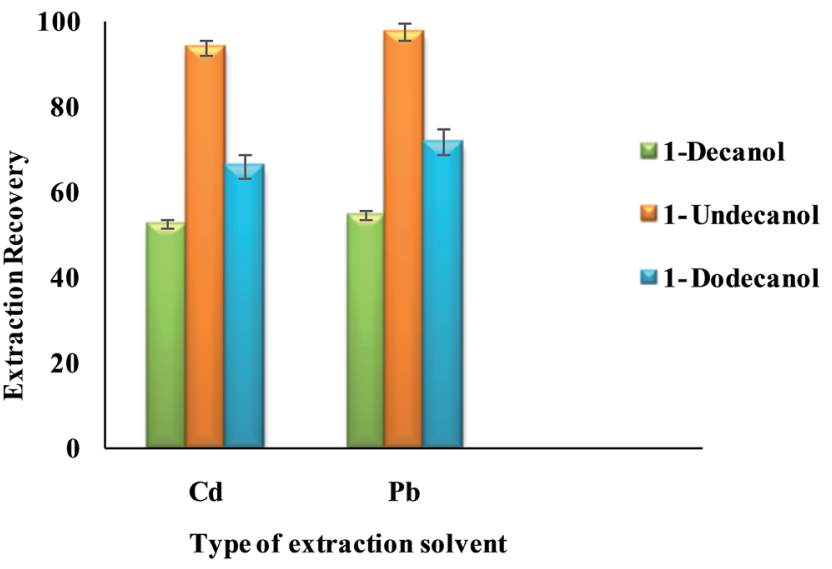

Fig. 7 Effect of type of extraction solvent on the extraction recovery of $\mathrm{Pb}^{2+}$ and $\mathrm{Cd}^{2+}$ obtained from DSPE-UAEME-SFO. Extraction conditions are similar to those of Fig. 4.

investigated in the range of $0.002-0.040 \%(\mathrm{v} / \mathrm{v})$ and the results are shown in Fig. 6. As shown in Fig. 6, upon increase of DDTP up to $0.04 \%(\mathrm{v} / \mathrm{v})$, the extraction efficiency increased and kept constant upon further increase in concentration. Therefore, a concentration of $0.04 \%(\mathrm{v} / \mathrm{v})$ DDTP was selected as the best choice to prevent any interference.

3.2.2.2. Effect of type and volume of extraction solvent. Select a proper extraction solvent in UAEME is crucial. Extraction solvent should possess some properties as extraction capability of analytes, low solubility in water, low volatility, proper melting point around room temperature, no interference with the analytical techniques used for the determination of analyte, and a density lower than water. In this study, three different organic solvents were tested; including 1-decanol, 1-dodecanol and 1undecanol. Average extraction recovery $(n=5)$ and standard deviation (SD) for different extraction solvents are shown in

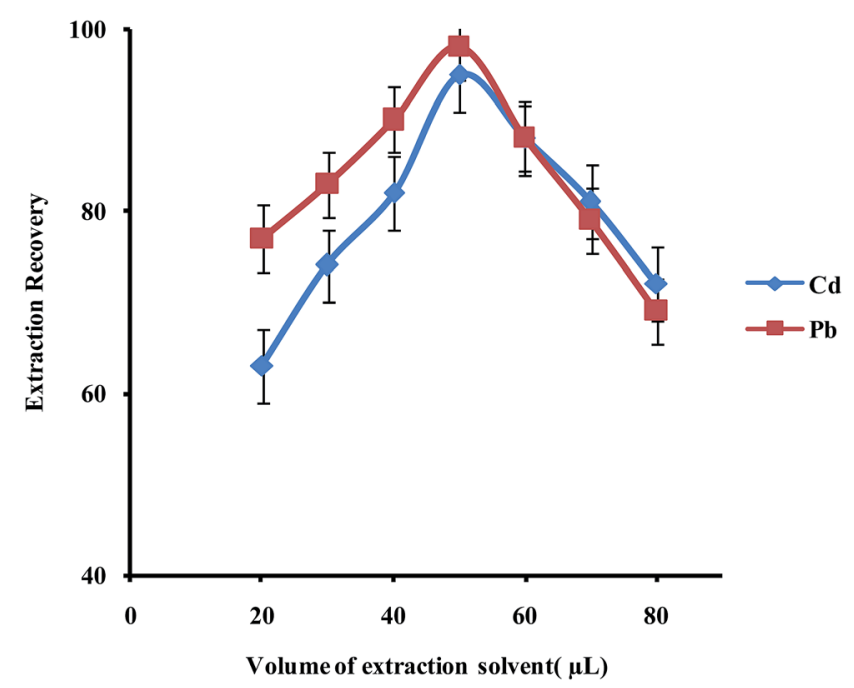

Fig. 8 Effect of volume of extraction solvent on the extraction recovery of $\mathrm{Pb}^{2+}$ and $\mathrm{Cd}^{2+}$ obtained from DSPE-UAEME-SFO. Extraction conditions are similar to those of Fig. 4. 


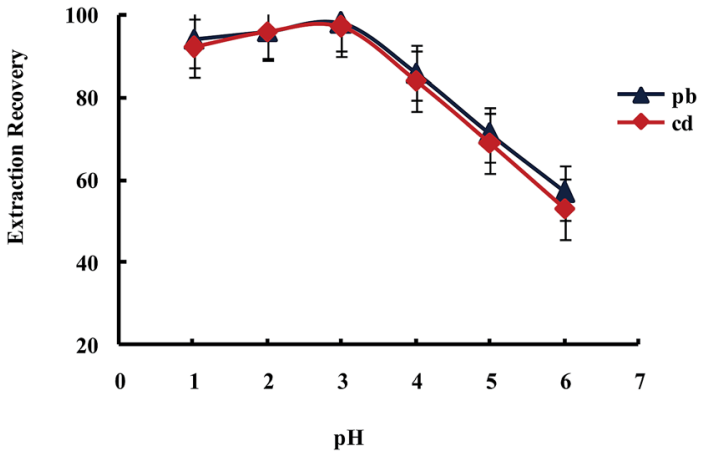

Fig. 9 Effect of $\mathrm{pH}$ on the extraction recovery of $\mathrm{Pb}^{2+}$ and $\mathrm{Cd}^{2+} \mathrm{ob}-$ tained from DSPE-UAEME-SFO. Extraction conditions are similar to those of Fig. 4.

Table 2 Effect of other ions on determination $\mathrm{Pb}^{2+}, \mathrm{Cd}^{2+}$ using DSPEUAEME-SFO; SD, standard deviation $(n=5)$

\begin{tabular}{lcll}
\hline & & \multicolumn{2}{l}{ Recovery $(\%) \pm \mathrm{SD}$} \\
\cline { 3 - 4 } Interferents & Foreign ions to & & $\mathrm{Cd}^{2+}$ \\
\hline $\mathrm{Na}^{+}$ & 1500 & $98.9 \pm 1.5$ & $98.7 \pm 2.8$ \\
$\mathrm{~K}^{+}$ & 1000 & $97.6 \pm 3.0$ & $97.5 \pm 2.2$ \\
$\mathrm{Mg}^{2+}, \mathrm{Ca}^{2+}, \mathrm{Fe}^{2+}$ & 500 & $98.3 \pm 1.3$ & $96.8 \pm 2.0$ \\
$\mathrm{Co}^{2+}, \mathrm{Ni}^{2+}, \mathrm{Zn}^{2+}, \mathrm{Mn}^{2+}$ & 400 & $98.7 \pm 1.2$ & $96.6 \pm 2.1$ \\
$\mathrm{Hg}^{2+}$ & 300 & $97.8 \pm 2.1$ & $97.1 \pm 3.9$ \\
$\mathrm{Cu}^{2+}, \mathrm{Fe}^{3+}$ & 200 & $95.4 \pm 2.0$ & $96.2 \pm 2.5$ \\
$\mathrm{Cr}^{3+}, \mathrm{Cr}^{6+}$ & 100 & $96.7 \pm 1.2$ & $97.8 \pm 2.4$ \\
\hline
\end{tabular}

Table 3 Analytical characteristics of DSPE-UASEME-GFAAS for determination of $\mathrm{Pb}^{2+}$ and $\mathrm{Cd}^{2+}$

\begin{tabular}{|c|c|c|}
\hline \multirow[b]{2}{*}{ Parameter } & \multicolumn{2}{|c|}{ Analytical feature } \\
\hline & $\mathrm{Pb}^{2+}$ & $\mathrm{Cd}^{2+}$ \\
\hline Linear range $\left(\mu \mathrm{g} \mathrm{L}^{-1}\right)$ & $0.001-15$ & $0.002-10$ \\
\hline$R^{2}$ & 0.988 & 0.991 \\
\hline Limit of detection $\left(\mathrm{ng} \mathrm{L}^{-1}\right)(3 \sigma, n=7)$ & 0.2 & 0.5 \\
\hline RSD $\%$ (inter-day, $n=7$ ) & 4.8 & 5.1 \\
\hline RSD $\%$ (inter-day, $n=7$ ) & 5.3 & 5.5 \\
\hline Enrichment factor & 1800 & 1800 \\
\hline Sample volume (mL) & 100 & 100 \\
\hline
\end{tabular}

Fig. 7. The results revealed that 1-undecanol has the highest extraction recovery in comparison with the other tested solvents. Therefore, 1-undecanol was selected for further experiments.
In order to examine the effect of the volume of the extraction solvent on the performance of the presented UAEME procedure, different volumes of 1-undecanol $(20,30,40,50,60,80 \mu \mathrm{L})$ were used. By increasing the volume of 1-undecanol from 20 to $80 \mu \mathrm{L}$, the volume of the floating organic drop increases from 16 to 74 $\mu \mathrm{L}$. It is clear that, by increasing the volume of 1 -undecanol, the extraction recovery increases and by further increasing of the extraction solvent volume, the extraction recovery slightly decreases because of dilution effect (Fig. 8) at higher volumes than $40 \mu \mathrm{L}$, extraction recovery slightly decreases whereas the enrichment factor found to decrease significantly. The volume of extractant solvent has to be selected to obtain high enrichment factor and extraction recovery. In the subsequent studies, $40 \mu \mathrm{L}$ of 1-undecanol was used as the optimal volume of the extraction solvent.

3.2.2.3. Effect of $p H$. In the extraction of metal ions, the complexing and extraction efficiency are closely related to the $\mathrm{pH}$ of the solution system.

Extraction of metal ions by UAEME involves complex formation with adequate hydrophobicity to be extracted into small volume of organic phase. It is clearly indicated that $\mathrm{pH}$ of the aqueous solution is an important factor for the quantitative recoveries of analytes and play a unique role on metal-chelate formation and subsequent extraction. In order to obtain the favorable complexing and preconcentration efficiency, the $\mathrm{pH}$ values were studied in the range of 1.0-7.0. The obtained results indicated that the extraction recovery of $\mathrm{Pb}^{2+}$ and $\mathrm{Cd}^{2+}$ remained more or less constant when the sample $\mathrm{pH}$ increased from $\mathrm{pH} 1$ to 3.0, and decreased significantly at higher $\mathrm{pH}$ values (Fig. 9). On the other hand, since an aqueous solution of DDTP is nearly acidic, within the optimized $\mathrm{pH}$ range (i.e., $\mathrm{pH}$ 3.1 in $100 \mathrm{~mL}$ aqueous solution), in this work, the use of an acidic solution for the $\mathrm{pH}$ adjustment was not needed.

3.2.2.4. Effect of ionic strength. Generally in liquid phase microextraction methods, addition of salt to aqueous solution causes a decrease in solubility of the analytes and enhances their partitioning into the organic phase (salting-out effect). To investigate the effect of ionic strength on UASEME (extraction recovery of $\mathrm{Pb}^{2+}$ and $\mathrm{Cd}^{2+}$ ) performance, different amounts of sodium chloride in a range of $0-10 \%(\mathrm{w} / \mathrm{v})$ were added to the sample solution. The obtained result indicated that the salt addition has no significant effect on the extraction recovery of $\mathrm{Pb}^{2+}$ and $\mathrm{Cd}^{2+}$. Therefore, subsequent experiments were done without any salt addition.

3.2.2.5. Effect of sonication time. In traditional dispersive liquid-liquid extraction, an organics solvent is applied to disperse the extraction solvent, but, as a result of the toxicity of

Table 4 Concentrations of $\mathrm{Pb}^{2+}$ and $\mathrm{Cd}^{2+}$ found in certified references material

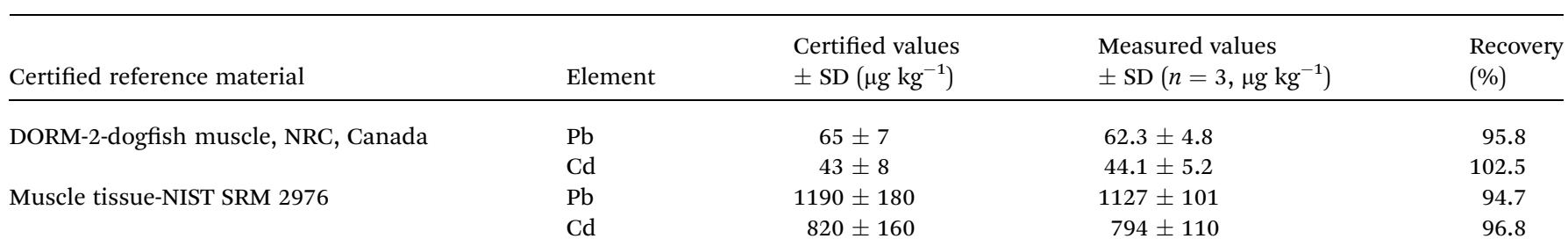


Table 5 Concentration of $\mathrm{Pb}^{2+}$ and $\mathrm{Cd}^{2+}$ in different real samples under optimal conditions

\begin{tabular}{|c|c|c|c|c|}
\hline Sample & Ion & Added $\left(\mu \mathrm{g} \mathrm{g}^{-1}\right)$ & Found mean $\pm \mathrm{SD}\left(\mu \mathrm{g} \mathrm{g}^{-1}\right)$ & Recovery\% \\
\hline \multirow[t]{4}{*}{ Human hair } & $\mathrm{Pb}$ & - & $26.47 \pm 0.12$ & - \\
\hline & & 23 & $27.16 \pm 0.15$ & 98.9 \\
\hline & $\mathrm{Cd}$ & - & $11.32 \pm 0.09$ & - \\
\hline & & 10 & $12.42 \pm 0.10$ & 100.8 \\
\hline \multirow[t]{4}{*}{ Cow milk } & $\mathrm{Pb}$ & - & $13.65 \pm 0.11$ & - \\
\hline & & 10 & $14.67 \pm 0.11$ & 100.1 \\
\hline & Cd & - & $23.41 \pm 0.16$ & - \\
\hline & & 23 & $24.32 \pm 0.20$ & 99.6 \\
\hline \multirow[t]{4}{*}{ Honey } & $\mathrm{Pb}$ & - & $0.13 \pm 0.04$ & - \\
\hline & & 1.0 & $1.11 \pm 0.06$ & 98.2 \\
\hline & $\mathrm{Cd}$ & - & $0.05 \pm 0.01$ & - \\
\hline & & 1.0 & $1.04 \pm 0.06$ & 99.0 \\
\hline \multicolumn{5}{|l|}{ Tea } \\
\hline \multirow[t]{4}{*}{ Ahmad } & $\mathrm{Pb}$ & - & $2.61 \pm 0.05$ & - \\
\hline & & 1.0 & $3.64 \pm 0.06$ & 100.8 \\
\hline & $\mathrm{Cd}$ & - & $0.21 \pm 0.03$ & - \\
\hline & & 1.0 & $1.19 \pm 0.04$ & 98.3 \\
\hline \multirow[t]{4}{*}{ Lipton } & $\mathrm{Pb}$ & - & $1.54 \pm 0.05$ & - \\
\hline & & 1.0 & $2.48 \pm 0.05$ & 97.6 \\
\hline & $\mathrm{Cd}$ & - & $0.12 \pm 0.02$ & - \\
\hline & & 1.0 & $1.10 \pm 0.05$ & 98.2 \\
\hline \multirow[t]{4}{*}{ Ckakoshsabz } & $\mathrm{Pb}$ & - & $0.53 \pm 0.03$ & - \\
\hline & & 1.0 & $1.49 \pm 0.06$ & 97.4 \\
\hline & $\mathrm{Cd}$ & - & $0.06 \pm 0.01$ & - \\
\hline & & 1.0 & $1.08 \pm 0.04$ & 101.8 \\
\hline \multicolumn{5}{|l|}{ Water } \\
\hline \multirow[t]{4}{*}{ Well } & $\mathrm{Pb}$ & - & n.d. & - \\
\hline & & 1.0 & $0.97 \pm 0.06$ & 97.0 \\
\hline & $\mathrm{Cd}$ & - & n.d. & - \\
\hline & & 1.0 & $0.98 \pm 0.07$ & 0.98 \\
\hline \multirow[t]{4}{*}{ Garasoo river } & $\mathrm{Pb}$ & - & $1.25 \pm 0.08$ & - \\
\hline & & 1.0 & $2.24 \pm 0.09$ & 99.5 \\
\hline & $\mathrm{Cd}$ & - & $0.67 \pm 0.05$ & - \\
\hline & & 1.0 & $1.65 \pm 0.06$ & 98.8 \\
\hline \multirow[t]{4}{*}{ Saymareh } & $\mathrm{Pb}$ & - & $0.53 \pm 0.04$ & - \\
\hline & & 1.0 & $1.56 \pm 0.06$ & 101.9 \\
\hline & $\mathrm{Cd}$ & - & $0.18 \pm 0.02$ & - \\
\hline & & 1.0 & $1.15 \pm 0.04$ & 97.4 \\
\hline \multicolumn{5}{|l|}{ Rice } \\
\hline \multirow[t]{4}{*}{ Feridonkenar } & $\mathrm{Pb}$ & - & $0.78 \pm 0.03$ & - \\
\hline & & 1.0 & $1.75 \pm 0.04$ & 98.3 \\
\hline & $\mathrm{Cd}$ & - & $0.03 \pm 0.01$ & - \\
\hline & & 1.0 & $1.04 \pm 0.04$ & 100.9 \\
\hline \multirow[t]{4}{*}{ Domsiah } & $\mathrm{Pb}$ & - & $4.17 \pm 0.08$ & - \\
\hline & & 1.0 & $5.15 \pm 0.09$ & 99.6 \\
\hline & $\mathrm{Cd}$ & - & $0.16 \pm 0.01$ & - \\
\hline & & 1.0 & $1.12 \pm 0.05$ & 97.4 \\
\hline \multirow[t]{4}{*}{ Tarom } & $\mathrm{Pb}$ & - & $1.52 \pm 0.05$ & - \\
\hline & & 1.0 & $2.43 \pm 0.06$ & 96.4 \\
\hline & $\mathrm{Cd}$ & - & $0.07 \pm 0.01$ & - \\
\hline & & 1.0 & $1.09 \pm 0.03$ & 101.9 \\
\hline \multicolumn{5}{|l|}{ Fish river } \\
\hline 1 & $\mathrm{~Pb}$ & - & $0.83 \pm 0.04$ & - \\
\hline & & 1.0 & $1.78 \pm 0.05$ & 97.2 \\
\hline & $\mathrm{Cd}$ & - & $0.35 \pm 0.02$ & - \\
\hline & & 1.0 & $1.32 \pm 0.06$ & 97.8 \\
\hline 2 & $\mathrm{~Pb}$ & - & $0.68 \pm 0.04$ & - \\
\hline & & 1.0 & $1.66 \pm 0.05$ & 98.8 \\
\hline & $\mathrm{Cd}$ & - & $0.19 \pm 0.01$ & - \\
\hline & & 1.0 & $1.21 \pm 0.05$ & 101.7 \\
\hline
\end{tabular}


Table 6 Comparison of the DSPE-UAEME-DLLME with some other methods reported for preconcentration and determination of $\mathrm{Pb}^{2+}$ and $\mathrm{Cd}^{2+}$

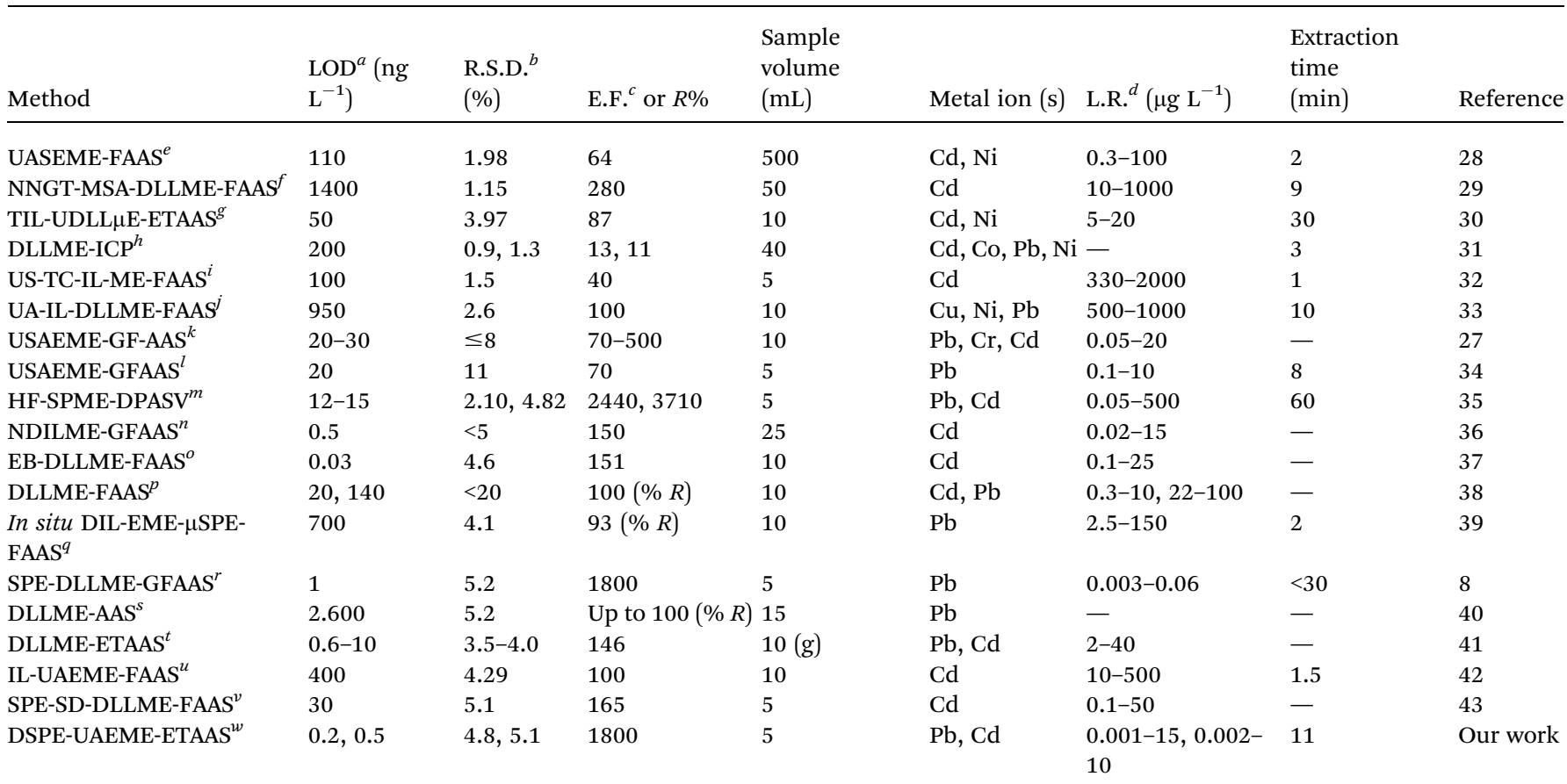

${ }^{a}$ LOD, limit of detection. ${ }^{b}$ RSD, relative standard deviation. ${ }^{c}$ E.F., enrichment factor. ${ }^{d}$ LR, linear range. ${ }^{e}$ UASEME-FAAS, ultrasound-assisted surfactant-enhanced-microextraction-flame atomic absorption spectrometry. ${ }^{f}$ NNGT-MSA-DLLME-FAAS, narrow neck glass tube-magnetic stirring-assisted dispersive liquid-liquid microextraction-flame atomic absorption spectrometry. ${ }^{g}$ TIL-UDLL $\mu$ E-ETAAS, temperature-controlled ionic liquid-based ultrasound-assisted microextraction-electro thermal atomic absorption spectrometry. ${ }^{h}$ DLLME-ICP, dispersive liquid-liquid microextraction-inductively coupled plasma. ${ }^{i}$ US-TC-IL-ME-FAAS, ultrasound-assisted temperature-controlled ionic liquid microextraction-flame atomic absorption spectrometry. ${ }^{j}$ UA-IL-DLLME-FAAS, ultrasonic-assisted and ionic liquid-based dispersive liquid-liquid microextraction-flame atomic absorption spectrometry. ${ }^{k}$ USAEME-GF-AAS, ultrasound-assisted emulsification microextraction-graphite furnace-atomic absorption spectrometry. ${ }^{l}$ USAEME-GFAAS, ultrasound-assisted emulsification-microextraction-graphite furnace atomic absorption spectrometry. ${ }^{m}$ HFSPME-DPASV, hollow-fiber solid/liquid phase microextraction-differential pulse anodic stripping voltammetry. ${ }^{n}$ NDILME-GFAAS, non-dispersive ionic liquid microextraction-graphite furnace atomic absorption spectrometry. ${ }^{\circ}$ EB-DLLME-FAAS, emulsification based-dispersive liquid-liquid microextraction-flame atomic absorption spectrometry. ${ }^{p}$ DLLME-FAAS, dispersive liquid-liquid microextraction-flame atomic absorption spectrometry. ${ }^{q}$ In situ DIL-EME- $\mu$ SPE-FAAS, in situ dicationic ionic liquid-emulsification microextraction-micro solid phase extraction flame atomic absorption spectrometry. ${ }^{r}$ Solid-phase extraction-dispersive liquid-liquid microextraction-graphite furnace atomic absorption spectrometry. ${ }^{s}$ Dispersive liquid-liquid microextraction-atomic absorption spectrometry. ${ }^{t}$ Dispersive liquid-liquid microextraction-electro thermal atomic absorption spectrometry. ${ }^{u}$ IL-UAEME-FAAS, ionic liquid-ultrasound assisted emulsification microextraction-flame atomic absorption spectrometry. ${ }^{v}$ SPE-SD-DLLME-FAAS, solid phase extraction-solvent-based de-emulsification-dispersive liquid-liquid microextraction-flame atomic absorption spectrophotometry. ${ }^{w}$ Dispersive solid phase extraction-ultrasound assisted emulsification microextraction-solidification of organic droplet-electrothermal atomic absorption.

these solvents, ultrasonic bath was used for the dispersion process. The ultrasound radiation is an effective tool to assist the emulsification phenomenon and accelerates the masstransfer process between two immiscible phases, leading to an increase in the extraction efficiency of the technique in a minimum amount of time. ${ }^{27}$ Sonication time is one of the important factors in UAEME. The effect of the sonication time was studied in the range of 0-7 min. The results showed that the extraction recoveries are increased by increasing the sonication time before $4 \mathrm{~min}$, and after that, remained nearly constant. Therefore, $4 \mathrm{~min}$ of sonication time was chosen in subsequent experiments.

3.2.2.6. Effect of centrifugation time. A centrifugation step was necessary for the phase separation. The effect of centrifugation times on extraction recovery of $\mathrm{Pb}^{2+}$ and $\mathrm{Cd}^{2+}$ ions was studied in the range of 1 to $10 \mathrm{~min}$ at a rate of $5500 \mathrm{rpm}$. The extraction recovery for $\mathrm{Pb}^{2+}$ and $\mathrm{Cd}^{2+}$ ions was lower when the centrifugation time was shorter than $3 \mathrm{~min}$. But, longer centrifugation has no remarkable effect on the extraction recovery of $\mathrm{Pb}^{2+}$ and $\mathrm{Cd}^{2+}$ ions. Hence $3 \mathrm{~min}$ (5500 rpm) was chosen in the subsequent experiments.

\subsection{Interference study}

The selectivity of the DSPE-UASEME for determination of $\mathrm{Pb}^{2+}$ and $\mathrm{Cd}^{2+}$ was evaluated. For this purpose, a series of experiments were designed using $100 \mathrm{~mL}$ of solution that contains 0.1 $\mu \mathrm{g} \mathrm{L}^{-1}$ of $\mathrm{Pb}^{2+}$ and $\mathrm{Cd}^{2+}$ and various amounts from interfering ions, were preconcentrated and determined. A given spices was considered to interfere if it resulted in a $\pm 5 \%$ variation of the GFAAS signal. The results obtained are given in Table 2. The results showed that interferences possess no obvious influence on the signal intensity of the analytes (Table 2). 


\subsection{Analytical figures of merit}

The analytical performance was investigated in terms of linearity, correlation coefficient, limit of detection (LOD), enrichment factor (EF) and reproducibility under optimized experimental conditions (Table 3 ). The calibration graphs were linear in the range 0.001-15 $\mu \mathrm{g} \mathrm{L}^{-1} \mathrm{~Pb}^{2+}, 0.002-10 \mu \mathrm{g} \mathrm{L}{ }^{-1} \mathrm{Cd}^{2+}$ under the optimum conditions of the proposed method. The limits of detection were $0.2 \mathrm{ng} \mathrm{\textrm {L } ^ { - 1 }}$ for $\mathrm{Pb}^{2+}$ and $0.5 \mathrm{ng} \mathrm{\textrm {L } ^ { - 1 }}$ for $\mathrm{Cd}^{2+}$, with a preconcentration factor of 1800 . It is noteworthy these limits of detections for the proposed extraction method are in the same order of magnitude as ICP-MS. While capital cost is somewhat lower for the method. Thus, the proposed extraction method seems to be preferable to other existing technology for determination of these elements (Table 3).

The repeatability (intra-day) and reproducibility (inter-day) of method were evaluated by carrying out seven replicate extraction and determination of $\mathrm{Pb}^{2+}$ and $\mathrm{Cd}^{2+}$ at a concentration level of $0.1 \mu \mathrm{g} \mathrm{L}^{-1}$ during a day (intra-day) and seven replicates at seven subsequent days (inter-day). The values of intraday RSD were 4.9 and 5.1 for $\mathrm{Pb}^{2+}$ and $\mathrm{Cd}^{2+}$ respectively. Regarding the inter-day RSD, 5.3 and 5.5 was obtained for $\mathrm{Pb}^{2+}$ and $\mathrm{Cd}^{2+}$ respectively.

\subsection{Analysis of fish certified reference material}

The accuracy of the proposed method for the extraction and determination of $\mathrm{Pb}^{2+}$ and $\mathrm{Cd}^{2+}$ ions was evaluated by determining the concentration of these ions in two fish certified reference material (DORM-2-dogfish muscle, NRC, Canada; Muscle tissue-NIST SRM 2976). The CRM samples were subjected to the DSPE-UAEME procedure. The obtained results are in good agreement with the certified values (Table 4).

\subsection{Analysis of real samples}

The proposed DSPE-UAEME combined with GFAAS methodology was applied for determination of $\mathrm{Pb}$ and $\mathrm{Cd}$ in different food and environmental samples. The results for fish, honey, Iranian rice, black tea, cow milk, human hair and water samples are given in Table 5. These samples was then spiked with the standards of $\mathrm{Pb}^{2+}$ and $\mathrm{Cd}^{2+}$ at different concentration levels and all experiments were performed in five replicate $(n=5)$. According to the results, the spiked $\mathrm{Pb}$ and $\mathrm{Cd}$ can be quantitatively recovered from all of the samples studied by the proposed procedure. These results demonstrate the applicability of the procedure for $\mathrm{Pb}$ and $\mathrm{Cd}$ determination in real samples.

\subsection{Comparison of DSPE-UAEME-SFO with previously reported methods}

In Table 6 are compared the performance characteristics of the proposed DSPE-UAEME-SFO method for determination of $\mathrm{Pb}^{2+}$ and $\mathrm{Cd}^{2+}$ in real samples with those of some other reported methods. It is clearly seen that the proposed method possesses a good sensitivity together with a suitable dynamic linear range and an improved limit of detection. In fact, the DSPE-UAEMESFO has higher enrichment factor (except ref. 35) and lower detection limit, than all the other methods (except ref. 37). The RSD values in the DSPE-UAEME-SFO are relatively low, the extraction time is relatively short and its enrichment factor is much higher than that of the previous methods. These characteristics are of great interest for the routine laboratories in the trace analysis of metal ions.

\section{Conclusions}

SBA-15/CCMet was synthesized and used as a new sorbent for simultaneous preconcentration and extraction of $\mathrm{Pb}^{2+}$ and $\mathrm{Cd}^{2+}$ in DSPE. It was characterized by TEM, and FT-IR techniques. In the present study, DSPE method was combined with UAEMESFO technique followed by GFAAS determination as a highly sensitive, accurate and reliable method for the preconcentration and determination of $\mathrm{Pb}^{2+}$ and $\mathrm{Cd}^{2+}$ in food and environmental samples. The limits of detection were $0.2 \mathrm{ng} \mathrm{L}^{-1}$ for $\mathrm{Pb}^{2+}$ and $0.5 \mathrm{ng} \mathrm{L}^{-1}$ for $\mathrm{Cd}^{2+}$, with a preconcentration factor of 1800 . It is noteworthy these limits of detections for the proposed extraction method are in the same order of magnitude as ICPMS. While capital cost is somewhat lower for the method. Thus, the proposed extraction method seems to be preferable to other existing technology for determination of these elements. This technique provides good precision, simplicity, multielement enrichment capability, ease of operation, environmentally friendly, good recovery and low detection limits within a relatively short time. The other benefits of the developed method were none-use of the organic disperser solvent, low cost and good accuracy and selectivity. As a conclusion, the proposed method possesses great potential in analysis of ultra trace $\mathrm{Pb}$ and $\mathrm{Cd}$ in real samples.

\section{Acknowledgements}

The authors thank the research council of Razi University of Kermanshah (Iran) for the financial support.

\section{References}

1 L. Abramsson-Zetterberg, A. C. Vikstrom, M. Tornqvist and K. E. Hellenas, Mutat. Res., Genet. Toxicol. Environ. Mutagen., 2008, 653, 50.

2 R. E. Rivas, I. López-García and M. Hernández-Córdoba, Microchim. Acta, 2009, 166, 355.

3 M. Brkljača, J. Giljanović and A. Prkić, Anal. Lett., 2013, 46, 2912.

4 M. Sadeghi, Z. Nematifar, M. Irandoust, N. Fattahi, P. Hamzei, A. Barati, M. Ramezani and M. Shamsipur, RSC Adv. , 2015, 5, 100511.

5 A. Bidari, E. Z. Jahromi, Y. Assadi and M. R. M. Hosseini, Microchem. J., 2007, 87, 6.

6 M. T. Naseri, M. R. M. Hosseini, Y. Assadi and A. Kiani, Talanta, 2008, 75, 56.

7 M. Shamsipur, N. Fattahi, Y. Assadi, M. Sadeghi and K. Sharafi, Talanta, 2014, 130, 26.

8 M. Shamsipur, N. Fattahi, M. Sadeghi, M. Pirsaheb and J. Iran, Chem. Soc. Rev., 2014, 11, 249. 
9 M. Shamsipur, M. Ramezani and M. Sadeghi, Microchim. Acta, 2009, 166, 235.

10 M. Rezaee, Y. Assadi, M. R. M. Hosseini, E. Aghaee, F. Ahmadi and S. Berijani, J. Chromatogr. A, 2006, 1116, 1.

11 M. Moradi, Y. Yamini, A. Esrafili and S. Seidi, Talanta, 2010, 82, 1864.

12 J. Regueiro, M. Liompart, C. Garcia-Jares, J. C. Garcia Monteagudo and R. Cela, J. Chromatogr. A, 2008, 1190, 27.

13 S. Nojavan, T. Gorji, S. Hosseiny Davarani and A. MortezaNajarian, Anal. Chim. Acta, 2014, 838, 51.

14 M. Dehghani, M. Abadi, N. Ashraf, M. Chamsaz and F. Shemirani, Talanta, 2012, 99, 1.

15 M. Anastassiades, S. J. Lehotay, D. Stajnbaher and F. J. Schenck, J. AOAC Int., 2003, 86, 412.

16 F. Hoffmann, M. Cornelius, J. Morell and M. Froba, Angew. Chem., Int. Ed., 2006, 45, 3216.

17 M. E. Davis, Nature, 2002, 417, 813.

18 Y. Shao, J. Guan, S. Wu, H. Liu, B. Liu and Q. Kan, Microporous Mesoporous Mater., 2010, 128, 120.

19 D. Y. Zhao, Q. S. Huo, J. L. Feng, B. F. Chmelka and G. D. Stucky, J. Am. Chem. Soc., 1998, 120, 6024.

20 A. Alizadeh, M. M. Khodaei, D. Kordestani, A. H. Fallah and M. Beygzadeh, Microporous Mesoporous Mater., 2012, 159, 9.

21 H. Veisi, D. Kordestani and A. R. Faraji, J. Porous Mater., 2014, 21, 141.

22 M. Shamsipur, M. Sadeghi, M. H. Beyzavi and H. Sharghi, Mater. Sci. Eng., C, 2015, 48, 424.

23 M. Tuzen and M. Soylak, J. Food Drug Anal., 2005, 13, 343.

24 F. Schuth and W. Schmidt, Adv. Mater., 2002, 14, 629.

25 W. J. Jones and W. J. Orville-Thomas, Trans. Faraday Soc., 1959, 55, 203.

26 P. J. Larkin, M. P. Makowski, N. B. Colthup and L. A. Flood, Vib. Spectrosc., 1998, 17, 53.
27 M. Aghamohammadi, M. Faraji, P. Shahdousti, H. Kalhora and A. Saleh, Phytochem. Anal., 2015, 26, 209.

28 M. Ezoddin, T. Taghizadeh and B. Majidi, Environ. Technol., 2014, 35, 2401.

29 A. Mohammadzadeh, M. Ramezani and A. Niazi, Desalin. Water Treat., 2016, 57, 9745.

30 S. S. Arain, T. Gul Kazi, A. J. Arain, H. I. Afridi, J. A. Baig, K. D. Brahman, N. Khan and S. A. Arain, Spectrochim. Acta, Part A, 2014, 138, 387.

31 E. Silva, L. Correia, L. Santos, E. Vieira and V. Lemos, Microchim. Acta, 2012, 178, 269.

32 V. Lemos and L. Oliveira, Food Control, 2015, 50, 901.

33 N. Jalbani and M. Soylak, Food Chem., 2015, 167, 433.

34 H. Jiang, Y. Zhang, B. Qiu and L. Wenhu, Clean: Soil, Air, Water, 2012, 40, 438.

35 Z. Es'haghi, H. Hoseini, S. Mohammadi-Nokhandani and J. Ebrahimi, J. Adv. Res., 2014, 5, 685.

36 N. Khan, T. Gul Kazi, M. Tuzen, F. Shah, H. I. Afridi and D. Citak, Anal. Chim. Acta, 2014, 812, 59.

37 M. Rahimi-Nasrabadi, M. Zahedi, S. Pourmortazavi, Z. Nazari, A. Banan and A. Asghari, Microchim. Acta, 2013, 180, 973.

38 F. Rosa, F. Duarte, J. Paniz, G. Heidrich, M. Nunes, E. Flores and V. Dressler, Microchem. J., 2015, 123, 211.

39 M. Shokri, A. Beiraghi and S. Seidi, Anal. Chim. Acta, 2015, 889, 123.

40 Z. A. Alothman, M. A. Habila, E. Yilmaz, I. Warad and M. Soylak, J. Anal. Chem., 2015, 70, 691.

41 I. López-García, Y. Vicente-Martínez and M. HernándezCórdoba, Talanta, 2014, 124, 106.

42 S. Khan, T. Gul Kazi and M. Soylak, Spectrochim. Acta, Part A, 2014, 123, 194.

43 M. Behbahani, A. Esrafili, S. Bagheri, S. Radfar, M. Kalate Bojdi and A. Bagheri, Measurement, 2014, 51, 174. 